\title{
ОСОБЛИВОСТІ КОНСТРУКЦІЇ ЧАСТИНИ СИЛОВОЇ ЕЛЕКТРОНІКИ В СОНЯЧНИХ МЕРЕЖЕВИХ ІНВЕРТОРАХ
}

\author{
М.М. Бордаков, аспірант
}

Інститут відновлюваної енергетики НАН України, 02094, вул. Гната Хоткевича, 20А, м. Київ, Україна.

При дослідженні роботи інвертора було визначено параметри, які впливають на ефективність його роботи. Одним з таких парметрів є внутрішні компоненти інвертора від яких залежить ефективність його роботи. Основним силовим компонентом є Power Stack (силовий модуль). Основним компонентом силового модуля є IGBT (біполярний транзистор з ізольованим затвором).

Даний тип транзисторів поєднує в собі характеристики двох напівпровідникових пристроїв:

- Біполярного транзистора (утворює силовий канал).

- Польового транзистора (утворює канал управління).

При розрахунку ефективності роботи інвертора потрібно розуміти як праџює його силова частина $і$ як силова частина перетворює постійний струм у змінний. Робота силових транзисторів керується драйвером, який пристрій керує частотою відкриття $і$ закриття транзисторів та вихідними характеристиками напруги інвертора.

Для регулювання роботи інвертора драйвер отримує сигнал та відправляє команду на сам силовий модуль. Таким чином відбувається регулювання вихідних параметрів інвертора. Для регулювання вихідної потужності інвертором також застосовується алгоритм зменшення вхідної потужності. Це досягається иляхом переходу робочої точки поля ФЕМ з точки МРРТ до робочої точки, ближчої до режиму холостого ходу сонячної панелі.

Регулювання рівня реактивної потужності також відбувається за рахунок роботи силового модуля. Для роботи інвертоpa, його силовий модуль повинен мати якісне охолодження. Охолодження має забезпечити відвід тепла від силового модуля, щуо в свою чергу попередить руйнування транзистора. В сучасних інверторах використовується активна і пасивна система охолодження. Зазвичай інвертори з пасивним охолодженням мають потужність до 100 кВт. Також у деяких виробніків є тестові моделі інверторів з водяним охолодженням. Потужність даних інверторів очікується більшою ніж 2500 кВт. Бібл. 10, рис. 5 .

Ключові слова: ефективність роботи, сонячна електростанція, навантаження, напруга, інвертор, струм.

\section{FEATURES OF DESIGN THE PART OF POWER ELECTRONICS IN SOLAR GRID ON INVERTERS}

\section{Bordakov, postgraduate student}

Institute of Renewable Energy of the National Academy of Sciences of Ukraine, 02094, 20A Hnata Khotkevycha St., Kyiv, Ukraine.

In the study of inverters have been identified parameters that affect its performance. One of the parameters is the internal components of the inverter on which the efficiency of its operation depends. The main power component is the Power Stack. The main component of the power module is the IGBT (bipolar insulated gate transistor).

This type of transistor combines the characteristics of two semiconductor devices:

- Bipolar transistor (forms a power channel).

- FET (forms a control channel).

When calculating the efficiency of the inverter, it is necessary to understand how its power part works and how the power time turns the direct current into an alternating current. The operation of the power transistors is controlled by the driver. This unit controls the frequency of opening and closing of the transistors and the output voltage characteristics of the inverter.

To control the inverters the driver receives a signal and sends a command to the power module itself. In this way the output parameters of the inverter are adjusted. To control the output power the inverter used an algorithm to reduce the input power. This is achieved by switching the FEM field operating point from the MPPT point to the operating point closest to the idle mode of the solar panel. Adjustment of the reactive power level is also due to the operation of the power module.

For the inverter to operate its power module must have good cooling. Cooling should ensure that the heat module is removed from the power module, which in turn will prevent the transistor from breaking down. Modern inverters use an active and passive cooling system. Usually passive cooling inverters have a capacity of up to $100 \mathrm{~kW}$. Some manufacturers also have thematic models of water cooled inverters. The power of these inverters is expected to be greater than $2500 \mathrm{~kW}$. Ref. 10, fig. 5 .

Keywords: efficiency, solar power, load, voltage, inverter, current. 


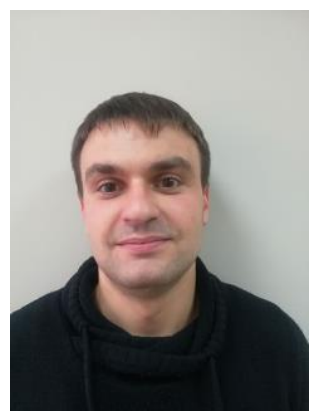

M.M. Бордаков M. Bordakov
Відомості про автора: аспірант IBE НАН України.

Освіта: НТУУ «КПІ ім. І. Сікорського» за спеціальністю: електротехніка та електротехнології. Отримав ступінь: молодшого інфженера-дослідника.

32016 аспірант IBE НАН України.

Наукова діяльність: сонячна енергетика, апаратна частина інвертора для сонячних панелей.

Публікації: 3.

ORCID: 0000-0002-2890-5632

Контакти: тел.: +380935669447

e-mail: $\underline{\text { m.m.bordakov@gmail.com }}$
Author information: postgraduate student Institute of Renewable Energy of the National Academy of Sciences of Ukraine.

Education: NTUU "Igor Sikorsky Kyiv Polytechnic Institute", specialty: electrical engineering and electrotechnology. Get a degree: junior research engineer.

Research area: solar energy, hardware part of solar panel inverter.

Publications: 3 .

ORCID: 0000-0002-2890-5632

Contacts: tel.: +38093 5669447

e-mail: m.m.bordakov@gmail.com
Перелік позначень та скорочень:

СЕС - Сонячна електростанція;

ВДЕ - Відновлювані джерела енергії;

Вступ. При дослідженні ефективності роботи інвертора було знайдено чинники, які впливають на дану величину. Одним 3 чинників $\epsilon$ внутрішні компоненти інвертора. Основним силовим компонентом є Power Stack (силовий модуль). Основним компонентом силового модуля $€$ IGBT (біполярний транзистор 3 ізольованим затвором). Даний тип транзисторів поєднує в собі характеристики двох напівпровідникових пристроїв:

- Біполярного транзистора (утворює силовий канал).

- Польового транзистора (утворює канал управління).

При розрахунку ефективності роботи інвертора потрібно розуміти як працює його силова частина і як силова частина перетворює постійний струм у змінний.

Опис схеми виконання інвертора. Основним завданням інвертора для сонячних панелей $\epsilon$ перетворення електричної енергії постійного струму у змінний струм. При роботі на мережу, інвертор ведеться нею. Він отримує данні від неї і працює синхронно з нею. На рис 1. Зображено типову схему заміщення інвертора.

На даній схемі видно, що перетворення здійснюється IBGT транзистором. Керуються вони так званим драйвером, драйвер подає сигнали на транзистори і задає форму вихідної кривої струму. В даній роботі розглянемо роботу саме IGBT транзистора.
ФЕС - Фотоелектрична станція; ФЕМ - Фотоелектричний модуль.

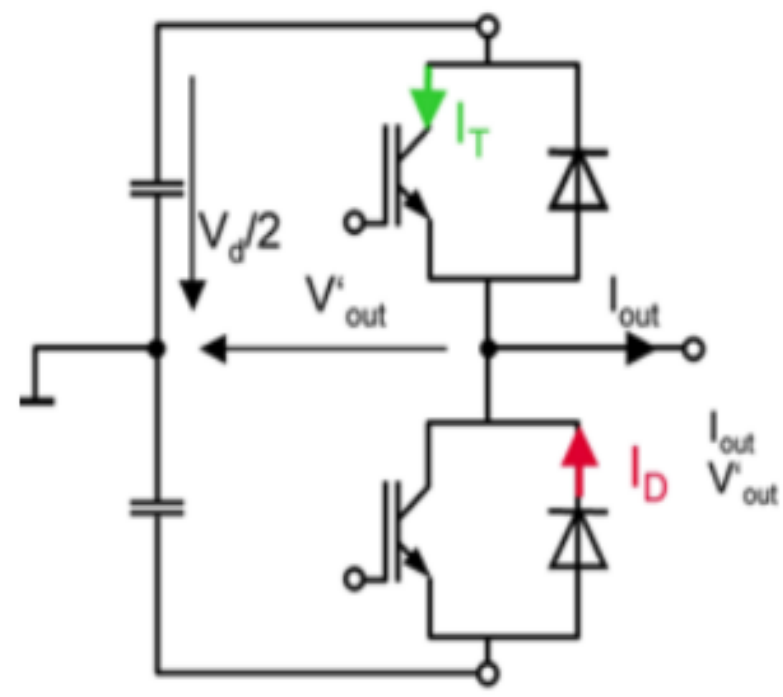

Рис. 1. Типова схема інвертора:

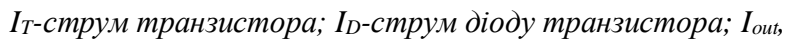
$V_{\text {out }}$ вихідні струм і напруга інвертора; $V_{d} / 2$ - половинчаста вхідна напруга.

Fig. 1. Typical diagram of solar inverter:

$I_{T}$ - ransistor current; $I_{D^{-}}$current of the transistor diode; $I_{\text {out }}$, $V_{\text {out }}$-output current and voltage of the inverter; $V_{d} / 2$ - half input voltage.

Опис структури та роботи IGBT транзистора. Даний транзистор складається 3 таких частин: p-n-p транзистора який керується $\mathrm{MOH}-$ транзистором через канал зв'язку n-типу. На рис.2 зображено еквівалентну схему IBGT транзистора. 


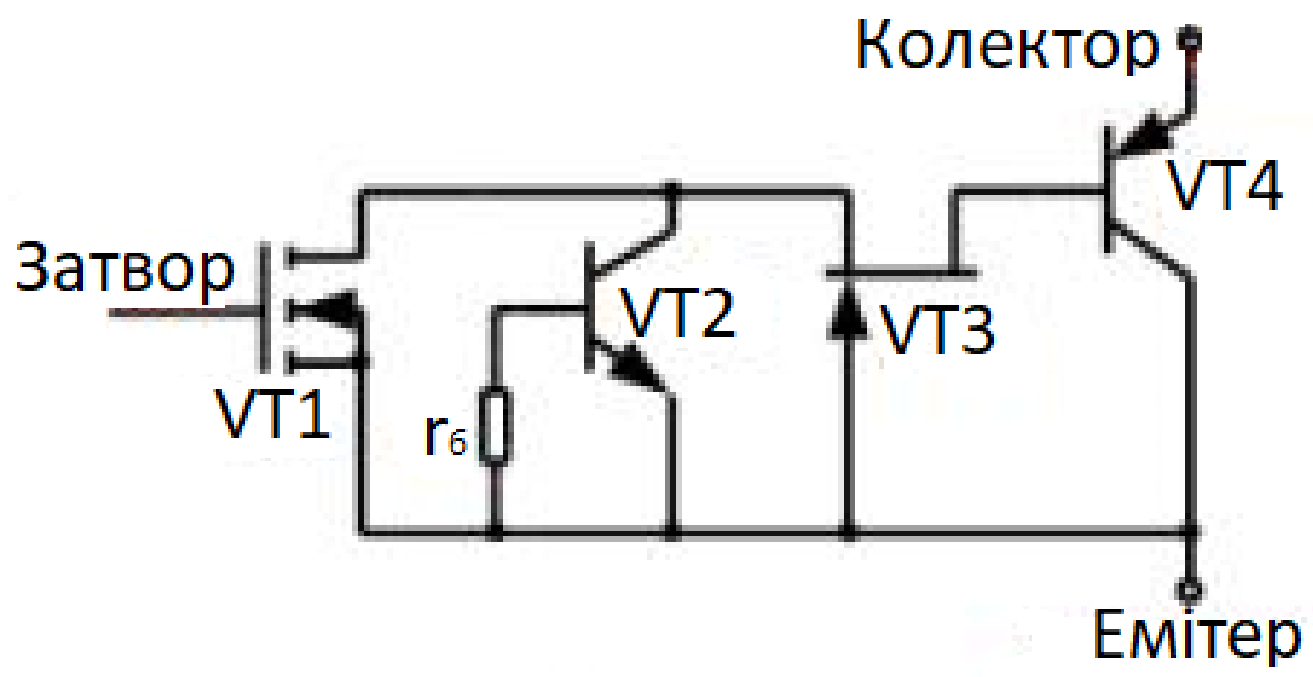

Рис. 2. Структурна схема IGBT транзистора.

Fig. 2. Structural diagram of IGBT tramsystor.

Колектор IGBT-транзистора на еквівалент-ній схемі (рис. 2) є емітером транзистора VT4. При подачі позитивної напруги на затвор у транзистора VT1 3'являється електропровідний канал. Через нього емітер транзистора IGBT (колектор транзистора VT4) з'єднується 3 базою транзистора VT4. Це призводить до того, що він повністю вимикається і падіння напруги між колектором транзистора IGBT і його емітером стає рівним падінню напруги на емітерному переході транзистора VT4, підсумованим 3 падінням напруги Uси на транзисторі VT1.
У зв'язку з тим, що падіння напруги на p-nпереході зменшується зі збільшенням температуpи, падіння напруги на відкритому IGBTтранзисторі в певному діапазоні струмів має негативний температурний коефіцієнт, який стає позитивним при великому струмі.

При збільшенні напруги, прикладеного до транзистора IGBT, збільшується струм каналу, який визначає струм бази транзистора VT4, при цьому падіння напруги на IGBT-транзисторі зменшується.

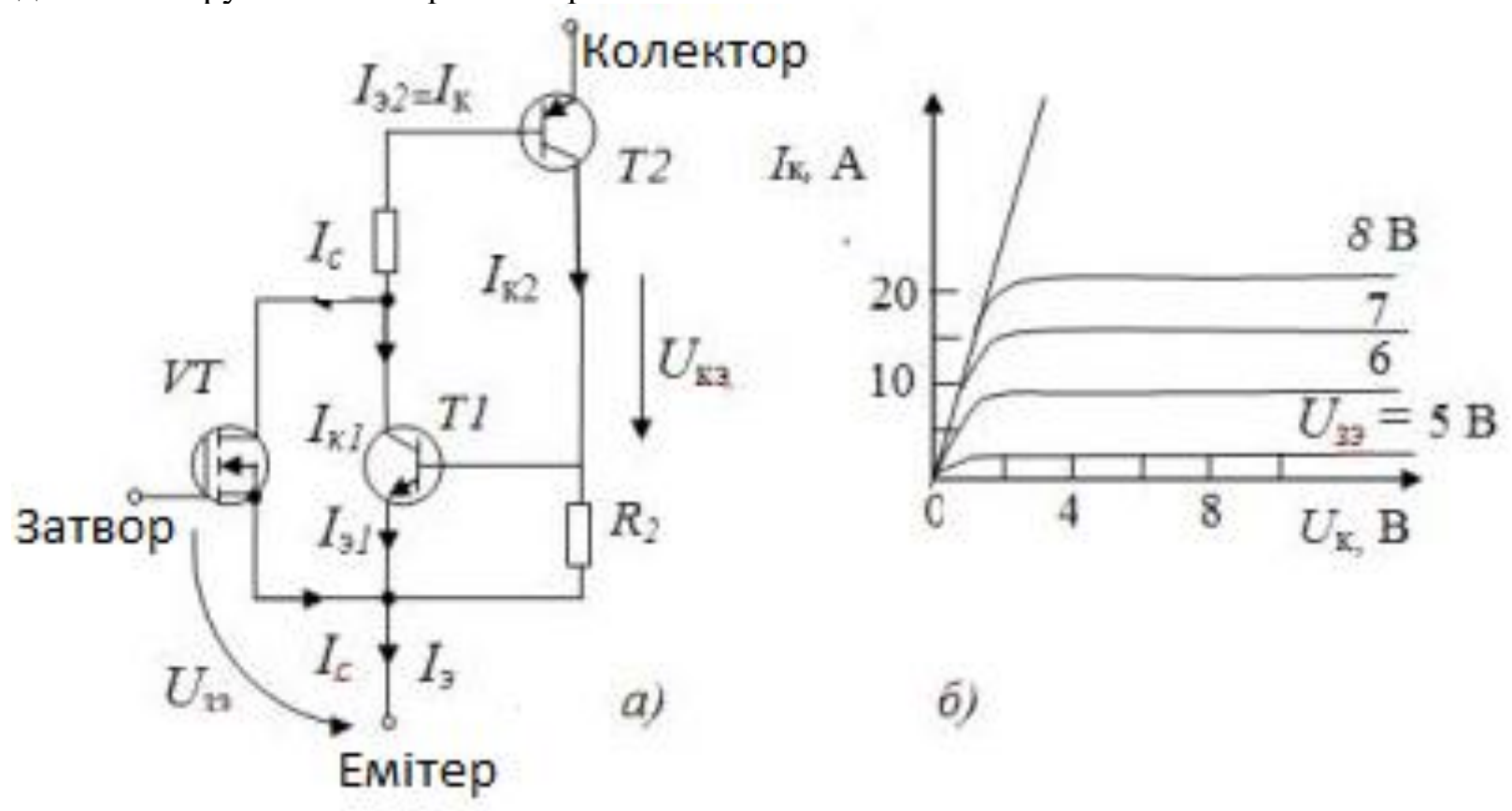

Рис. 3. Схема заміщення та вихідні характеристики ідеального IGBT.

Fig. 3. Replacement diagram and output characteristics of an ideal IGBT. 
При замиканні транзистора VT1 струм транзистора VT4 стає малим, що дозволяє вважати його замкненим. Додаткові шари введені для виключення режимів роботи, характерних для тиристорів, коли відбувається лавинний пробій. Буферний шар $\mathrm{n}+\mathrm{i}$ широка базова область $\mathrm{n}$ - забезпечують зменшення коефіцієнта посилення за струмом p-n-p-транзистора.
Загальна картина ввімкнення та вимикання транзистора досить складна, так як відбувається зміна рухливості носіїв заряду, коефіцієнтів передачі струму транзисторів, зміни опорів областей та ін. Хоча в принципі IGBT-транзистори можуть бути використані для роботи в лінійному режимі, але в основному їх застосовують в ключовому режимі.

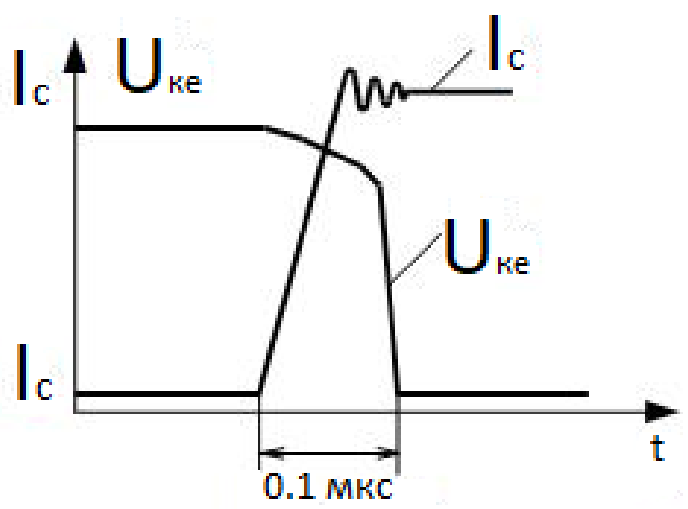

Рис. 4. Зміна падіння напруги Uке і струму Iс IGBT-транзистора.

Fig. 4. Change in voltage drop of Uke and current Ic of IGBT transistor.

Дослідження показали, що для більшості транзисторів типу IGBT час ввімкнення і вимкнення не перевищує 0,5 - 1,0 мкс. Для зменшення кількості додаткових зовнішніх компонентів до склада IGBT-транзисторів вводять діоди або випускають модулі, що складаються 3 декількох компонентів.

Процес перетворення і втрати під час роботи IGBT. Процес рекомбінації $\mathrm{Q}_{s}$ позитивно заряджених частин під час проходження негативно зарядженої зони транзистора має майже лінійну залежність на малих струмах і зі збільшенням струму до номінального і в режимі над струмів описується функцією квадратного кореня.

$\left.\mathrm{Q}_{\mathrm{s}} \sim\right|^{0.8 .1}$ робота на малих струмах.

$\left.\mathrm{Q}_{\mathrm{s}} \sim\right|^{0.5}$ робота на номінальних і над струмах.

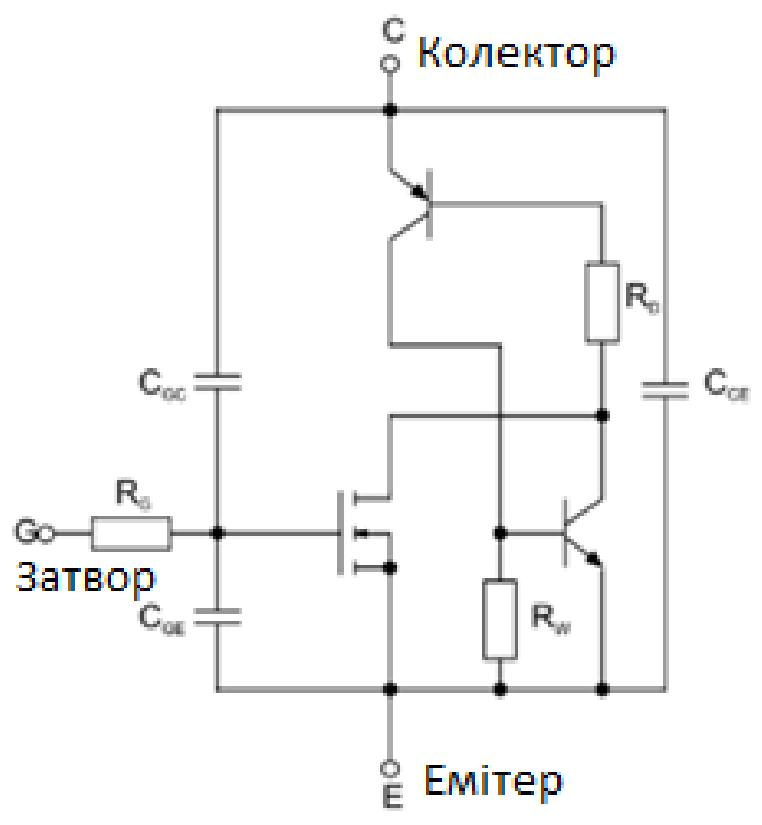

Рис. 5. Еквівалентна схема реального IGBT транзистора.

Fig. 5. Equivalent diagram of real IGBT transistor. 
Процеси накопичення зберігання та віддача заряду супроводжуються так званими комутаційними втратами. Час зберігання еквівалентний часу закриття транзистора, процес закриття (відключення) супроводжується появою "хвостового струму” в колекторі. Для того, щоб зрозуміти втрати в IGBT транзисторі потрібно розглянути структурну схему реального транзистора та оцінити всі паразитичні елементи в ній (рис.5).

При роботі транзистора паразитичні елементи і $\epsilon$ основним джерелом втрат. Але крім внутрішніх ємностей та опорів, еквівалентна схема також показує так званий "ідеальний MOSFET". Транзистор NPN на стороні затвора: $n$ + область випромінювача (емітер) / p + свердловина (база) / n-зона дрейфу (колектор) з бічним опором $\mathrm{p}+$ свердловини нижче зони емітера як опорний випромінювач RW i - у послідовності $\mathrm{p}$ + -колекторна площа (емітер) / n-зона дрейфу (основа) / p + свердловина (колектор) - транзистор PNP, який, у поєднанні з транзистором NPN утворює тиристорний ланцюг. Цей паразитичний тиристор чинить вплив на роботу, як тільки буде виконано наступну умову замикання:

$$
M \cdot\left(\alpha_{n p n}+\alpha_{p n p}\right)=1, \alpha_{n p n}, \alpha_{p n p}=\alpha_{T} \cdot \gamma_{E},
$$

де: $\mathrm{M}$ - коефіцієнт множення; $\alpha_{n p n}, \alpha_{p n p} \quad-$ коефіцієнти підсилення струму індивідуального транзистора в колі бази; $\alpha_{T}-$ фактор транспорту бази; $\gamma_{E}$ - ефективність емітера.

Це призвело б до втрати керованості IGBT i до його руйнування. В принципі, це може статися під час роботи в стаціонарному режимі (при перевищенні критичної щільності струму, яка зменшується в міру підвищення температури мікросхеми) або навіть під час відключення (динамічний зсув струму за рахунок збільшення струму порівняно зі стаціонарним режимом спрацювання). Відповідні проектні заходи надійно запобігають засувці у всіх сучасних типах IGBT при будь-яких допустимих статичних i динамічних умовах роботи; замикання відбудеться лише під час відключення, якщо б була номінальна щільність струму помножена на значення.

Відповідними проектними заходами $є$, наприклад, зменшення опору базового випромінювача RW.

Висновки та подальші дослідження. 3 поданого в статті матеріалу робимо висновки що:

1. Втрати в силовій частині інвертора досягаються в основному за рахунок паразитичних складових самого транзистора.
2. Втрати збільшуються як що виконується рівність 1.

При розрахунку інвертора потрібно враховувати втрати в силовому модулі. Також зважати на рівність 1. В подальшому, на основі даної статті, буде розроблена математична модель інвертора та порівняння іiї з реальним інвертором.

1. Wintrich A., Nicolai U., Tursky W., Reimann $T$. Application Manual Power Semiconductors. SEMIKRON International GmbH. 2015. 464 p.

2. ДСТУ 8635:2016. Площадки для фотоелектричних станцій. Приєднання станцій до електроенергетичної системи. Київ. ДП «УкрНДНЦ». 2017. С. 22. [Електронний ресурc]. URL:

http://eom.com.ua/index.php?action=downloads;sa=downfile\&id $=3656$.

3. Reactive Power Interconnection Requirements for PV and Wind Plants. Recommendations to NERC. [Електронний pecypc]. URL: https://prod-ng.sandia.gov/techlib-noauth/accesscontrol.cgi/2012/121098.pdf.

4. Brown T. Transmission network loading in Europe with high shares of renewables. IET Renewable Power Generation. Vol. 9. No. 1. Pp. 57-65.

5. GB/T19964-2012. Photovoltaic power plant power system access technical requirements. Beijing. General Administration of Quality Supervision. Inspection and Quarantine of Peoples Republic of China. China National Standardization Management Committee. 2012.

6. Campbell M., Aschenbrenner P., Blunden J., Smeloff E., Wright $S$. The drivers of the levelized cost of electricity for utility-scale photovoltaics. SunPower Corp. 200 p.

7. Zhou J., Gole A. VSC transmission limitations imposed by $\mathrm{AC}$ system strength and $\mathrm{AC}$ impedance characteristics. in Proc. 10th IET International Conference on AC and DC Power Transmission (ACDC). 2012. Pp. 1-6.

8. Collins L., Ward J. Real and reactive power control of distributed PV inverters for overvoltage prevention and increased renewable generation hosting capacity. Renewable Energy. 2015. Vol. 81. Pp. 464-471.

9. Utility-scale solar photovoltaic power pants-A project developers guide. International Finance Corporation (IFC). 2015.

10. Molina-Garcia A., Mastromauro R.A., GarciaSanchez T., Pugliese S., Liserre M., Stasi S. Reactive power flow control for PV inverters voltage support in LV distribution networks. IEEE Trans. Smart Grid. 2017. Vol. 8. No. 1. Pp. 447-456.

\section{REFERENCES}

1.Wintrich A., Nicolai U., Tursky W., Reimann T. Application Manual Power Semiconductors. SEMIKRON International GmbH. 2015. 464 p. [in English].

2.DSTU 8635:2016. Ploshchadky dlya fotoelektrychnykh stantsiy. Pryyednannya stantsiy do elektroenerhetychnoyi systemy. [Areas for photovoltaic plants. Interconnecting plants with the grid]. Kyiv. DP«UkrNDNTS». [Electronic resource]. URL: http://eom.com.ua/index.php?action=downloads;sa=downf ile\&id=3656. [in Ukrainian].

3. Reactive Power Interconnection Requirements for PV and Wind Plants. Recommendations to NERC. [Electronic resource]. URL: $\quad$ https://prod-ng.sandia.gov/techlib-noauth/accesscontrol.cgi/2012/121098.pdf. [in English].

4.Brown T. Transmission network loading in Europe with high shares of renewables. IET Renewable Power Generation. Vol. 9, No. 1. Pp. 57-65. [in English]. 
5.GB/T19964-2012. Photovoltaic power plant power system access technical requirements. Beijing. General Administration of Quality Supervision. Inspection and Quarantine of Peoples Republic of China. China National Standardization Management Committee. 2012. [in English].

6.Campbell M., Aschenbrenner P., Blunden J., Smeloff E., Wright $S$. The drivers of the levelized cost of electricity for utility-scale photovoltaics. SunPower Corp. 200 p. [in English].

7.Zhou J., Gole A. VSC transmission limitations imposed by $\mathrm{AC}$ system strength and $\mathrm{AC}$ impedance characteristics. in Proc. 10th IET International Conference on $\mathrm{AC}$ and $\mathrm{DC}$ Power Transmission (ACDC). 2012. Pp. 1-6. [in English].

8.Collins L., WardJ. Real and reactive power control of distributed PV inverters for overvoltage prevention and increased renewable generation hosting capacity. Renewable Energy. 2015. Vol. 81. Pp. 464-471. [in English].

9.Utility-scale solar photovoltaic power pants-A project developers guide. International Finance Corporation (IFC). 2015. [in English].

10. Molina-Garcia A. , Mastromauro R.A., Garcia-Sanchez, T., Pugliese S., Liserre M., Stasi S. Reactive power flow control for PV inverters voltage support in LV distribution networks. IEEE Trans. Smart Grid. 2017. Vol. 8. No. 1. Pp. 447-456. [in English].

\section{ОСОБЕННОСТИ КОНСТРУКЦИИ ЧАСТИ СИЛОВОЙ ЭЛЕКТРОНИКИ В СОЛНЕЧНЫХ СЕТЕВЫХ ИНВЕРТОРАХ}

\section{Н.Н. Бордаков, аспирант}

Институт возобновляемой энергетики НАН Украины, 02094, ул. Гната Хоткевича, 20А, Киев, Украина.

При исследовании работы инвертора были определены параметры которые влияют на эффективность его работы. Одним из параметров есть внутренние компоненты инвертора от которых зависит эффективность его работы.
Основным силовым компонентом является Power Stack (cuловой модуль). Основнылм компонентом силового модуля является IGBT (биполярный транзистор с изолированным затвором).

Данный тип транзисторов сочетает в себе характеристики двух полупроводниковых устройства:

- биполярного транзистора (образует силовой канал).

- Полевого транзистора (образует канал управления).

При расчете эффективности работы инвертора нужно понимать как работает его силовая часть и как силовая часть преобразует постоянный ток в переменный. Работа силовых транзисторов руководствуется драйвером, данное устройство управляет частотой открытия и закрытия транзисторов и выходными характеристиками напряжения инвертора.

Для регулирования работь инвертора драйвер получает сигнал и отправляет команду на сам силовой модуль. Таким образом происходит регулирование выходных параметров инвертора. Для регулирования выходной мощности инвертора применяется алгоритм уменьшения входной мощности. Это достигается путем перехода рабочей точки поля ФЭМ с точки МРРТ к рабочей точки, близкой к режиму холостого хода солнечной панели.

Регулировка уровня реактивной мощности также происходит за счет работы силового модуля. Для работы инвертора, его силовой модуль должен иметь качественное охлаждение. Охлаждение должно обеспечить отвод тепла от силового модуля в свою очередь предупредит разрушения транзистора. В современных инверторах используется активная и пассивная система охлаждения. Обычно инверторы с пассивным охлаждением имеют мощность до 100 кBm. Также у некоторых производителей есть тестовые модели инверторов с водяным охлаждением. Мощность данных инверторов ожидается больше 2500 кВт. Библ. 10, рис. 5.

Ключевые слова: эффективность работы, солнечная электростанция, нагрузка, напряжение, инвертор, ток.

Стаття надійшла до редакції 18.11.19 Остаточна версія 13.03.20 